\title{
Computational Finite Element Modelling of Structural Behaviours of Precast Sandwiched Foamed Concrete Slab
}

\author{
Kingsley Ukanwa', Noridah Mohamad', James B. P. Lim ${ }^{1}$ \\ ${ }^{1}$ Department of Civil and Environmental Engineering, University of Auckland, Auckland, New Zealand \\ ${ }^{2}$ Department of Civil and Environmental Engineering, University Tun Hussein Onn Malaysia, \\ Batu Pahat, Malaysia \\ Email: ukanwakingsley@gmail.com, noridah@uthm.edu.my, james.lim@auckland.ac.nz
}

Received 7 February 2015; accepted 5 June 2015; published 9 June 2015

Copyright (C) 2015 by authors and Scientific Research Publishing Inc.

This work is licensed under the Creative Commons Attribution International License (CC BY). http://creativecommons.org/licenses/by/4.0/

(c) (i) 0pen Access

\begin{abstract}
The structural behaviour of Precast Lightweight Foamed Concrete Panel (PLFP) under flexural load is investigated by using ABAQUS 6.13. The PLFP is made up of two Whyte's with a polystyrene insulator placed in between them using a double shear truss connector of diameter $6 \mathrm{~mm}$ placed at an angle $45^{\circ}$. The panel is reinforced with both vertical and horizontal steel reinforcement of 9 mm diameter. Four panels with varying dimensions are simulated to investigate their Ultimate Strength and Load-deflection profile. The results show that the length to thickness ratio of the panel is the major contributing factor to the ultimate strength of the PLFP. From the load deflection curve, the panel with the least deflection has the highest thickness which also results in a high ultimate strength recorded at $34.43 \mathrm{KN}$.
\end{abstract}

\section{Keywords}

Foamed Concrete, Flexural Behaviour, Finite Element, ABAQUS

\section{Introduction}

A concrete slab is an element member of a modern structural building. The horizontal slab is mostly used to construct the floors or ceiling while the thinner and vertical slabs are used for exterior paving or walls. In many domestic and industrial buildings, a thick concrete slab supported on foundations or directly on the subsoil is used to construct the ground floor of a building. These can either be "ground-bearing" or "suspended" slabs. In high rise buildings and skyscrapers, thinner pre-cast concrete slabs are slung between the steel frames to form 
the floors and ceilings on each level. Structural lightweight aggregate has been successfully used for well over two millennia; it has had widespread use for the past ninety years.

This track record of proven performance has demonstrated how structural lightweight aggregate contributes to the sustainable development by conserving energy, lowering transportation requirements, maximizing design and construction efficiency and increasing the service life of the product it is used in [1]. Foam concrete does not contain coarse aggregate, and can be regarded as an aerated mortar. Typically, foamed concrete is made by introducing air or other gases into a cement slurry and fine sand. In commercial practice, the sand is placed by pulverized fuel ash or other siliceous materials, and lime may be used instead of cement [2]. A sandwich panel is a three-layer element comprising of two thin flat facing plates of high-strength material and between which a thick lightweight core of low average strength is attached [3].

Flores-Johnson \& Li [4] computed numerically the simulation of sandwich panels in four-point bending. The numerical simulation was employed as a tool to understand the effects of face/core bonding and fasteners on the structural behaviour of the sandwich panels, which were not experimentally investigated due to the limited amount of tests available. It was observed that the face/core bonding plays a crucial role in the structural performance while the contribution of fastening is negligible. This indicates that improvement of the face/core bonding should be addressed when foamed concrete core is used to obtain optimum structural performance of composite sandwich panels. Mohamad [5] carried out series of tests on the PLFP under axial load till failure. Fourteen PLFP panels with various slenderness ratios were tested and also panels with similar dimensions were simulated under similar axial loads. It was observed that most panels finally failed by crushing of concrete at either one or both ends of the panel. The first crack occurred at $30 \%$ to $70 \%$ of the ultimate load. The ultimate strength obtained from FEM is higher but within an acceptable accuracy with the values of the experiments. The load-deflection profile showed that the width of the panels deflected together especially in the panels with higher slenderness ratio. These panels also recorded higher deflection measurements than panels with lower H/t. The Loaded-deflection behaviour shows that panels carry load as partially composite panels under service loads and the shear connector seemed to manage to transfer the load. Khalil [6] conducted an experimental research on four PLFP panels having length and width of $2000 \mathrm{~mm}$ and $750 \mathrm{~mm}$ respectively to obtained the ultimate strength by recording the load applied on PLFP at failure. It was observed that the ultimate strength achieved in the PLFP panels did not depend on just one factor alone, but several factors contributed to the panel's ultimate strength capacity which includes the panel's aspect ratio, diameter of its reinforcement and shear connector, Panel 1 and Panel 2 with $100 \mathrm{~mm}$ thickness each achieved the ultimate flexural strength of $10.83 \mathrm{kN}$ and 8.23 $\mathrm{kN}$ respectively while Panel 3 and Panel 4 with $110 \mathrm{~mm}$ thickness each achieved the ultimate flexural strength of $24.03 \mathrm{kN}$ and $25.63 \mathrm{kN}$ respectively. This shows that the thickness contributes to the increase in ultimate strength. From this study, a deeper and clear insight on the behaviour and failure mechanisms of the PLFP under flexural load will be very well understood. The result from this study is very important for the design of PLFP slab because it would be used as a guide to evaluate the structural behaviour in term of its crack pattern, loaddeflection profile and also recommendation for further studies.

\section{Finite Element Model of PLFP}

\subsection{General Overview}

Three (3) dimensional finite element models were developed to study the structural behaviour of the PLFP using four points bending test. The finite element results were validated by comparing the values obtained with the experimental results and theoretical calculation. ABAQUS 6.13 [7] was the software used for creating and analysing of the models. ABAQUS [7] is a very powerful engineering simulation program that has been adopted in recent years for solving challenging non-linear simulations. Extensive libraries of element types and list of material models can be found in ABAQUS documentation, this helps in the simulation of any kind of engineering materials. For non-linear simulations, the necessary parameters are the geometry, boundary conditions, material characteristics and loads. Load increments and related tolerances in non-linear analysis are automatically given by the software. A 3D nonlinear quasi static finite element model was developed using ABAQUS Dynamic/Explicit module to study the flexural behaviour of PLFP. Material properties of foamed concrete obtained from previous experiment were used to calculate the concrete damage plasticity (CDP) parameters. The parameters were calculated based on the relationship between the stress-strain tension and compression loading. 


\subsection{Foamed Concrete Materials}

The foamed concrete is composed of inner and outer wythe with different concrete densities. The concrete damage plasticity, available in ABAQUS 6.13 [7] was used as the parameter for modelling the foamed concrete. Table 1 shows the values used in computing the CDP for the foamed concrete. Using results obtained by Mohamad et al. [8], the equation for calculating the concrete damage plasticity parameters is $\mathrm{D}=1-\left(\mathrm{E} / \mathrm{E}_{0}\right)$, where $\mathrm{D}$ is the damage parameter of foamed concrete in compression and tension, $\mathrm{E}_{0}$ is the initial (undamaged) elastic stiffness and $\mathrm{E}$ is the damaged elastic stiffness of the foamed concrete with compressive strength of 10MPa

\subsection{Steel Reinforcement Modelling}

There were both horizontal and vertical reinforcements at top and bottom with diameter bar $9 \mathrm{~mm}$ of yield strength $559 \mathrm{MPa}$ and tied to each other at $300 \mathrm{~mm}$ centre to centre. The material properties summarised in Table 2 was used in modelling the steel reinforcement in the PLFP.

\subsection{Shear Connector Modelling}

Three $6 \mathrm{~mm}$ mild steel double shear truss connector bent to an angle $45^{\circ}$ were used for each panel to transfer the load from one wythe to the other. The double shear truss connectors were joined to the vertical reinforcement in the steel mesh. This shear connector had yield stress of $518 \mathrm{MPa}$, tensile strength of $544.28 \mathrm{MPa}$ and young modulus of $197.8 \mathrm{GPa}$. The shear connectors where arranged in such a way that they were evenly spaced across the width of the PLFP slab (Figure 1).

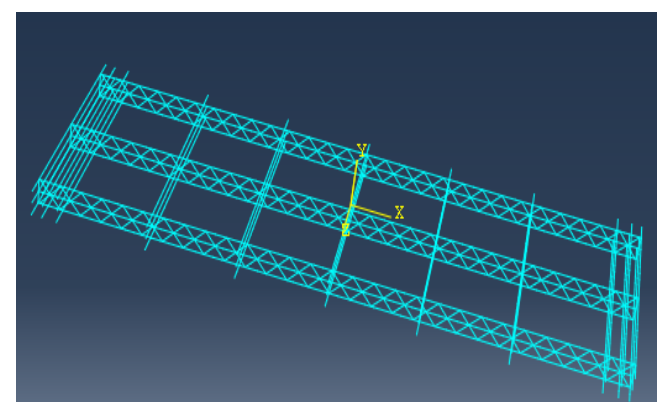

Figure 1. Shear connector and reinforcement arrangements.

Table 1. Concrete damaged plasticity of foamed concrete. [8].

\begin{tabular}{|c|c|c|c|c|c|}
\hline Dilatation angle & Eccentricity & \multicolumn{2}{|c|}{ Initial/biaxial/uniaxial ratio, $\sigma \mathrm{c}_{0} / \sigma \mathrm{b}_{0}$} & $\mathrm{~K}$ & Viscosity \\
\hline $27^{\circ}$ & 0.1 & 1.16 & & 1 & 0 \\
\hline \multicolumn{3}{|c|}{ Compressive behaviour from experiment } & \multicolumn{3}{|c|}{ Tensile behaviour from experiment } \\
\hline Yield stress (MPa) & Inelastic strain & Damage parameter, D & Yield stress (MPa) & Cracking strain & Damage parameter, D \\
\hline 8.751 & 0 & 0 & 0.861 & 0 & 0.000 \\
\hline 9.850 & 0.0017 & 0 & 0.776 & 0.00159 & 0.204 \\
\hline 10.356 & 0.0033 & 0 & 0.605 & 0.00409 & 0.476 \\
\hline 10.032 & 0.0041 & 0.215 & 0.518 & 0.00526 & 0.582 \\
\hline 9.714 & 0.0047 & 0.337 & 0.431 & 0.00638 & 0.673 \\
\hline 9.357 & 0.0055 & 0.456 & 0.345 & 0.00746 & 0.752 \\
\hline 8.734 & 0.0066 & 0.577 & 0.259 & 0.00854 & 0.824 \\
\hline 7.725 & 0.0078 & 0.682 & 0.173 & 0.00966 & 0.889 \\
\hline 5.450 & 0.0127 & 0.862 & 0.086 & 0.01082 & 0.947 \\
\hline 3.962 & 0.0194 & 0.934 & 0 & 0.01202 & 1.000 \\
\hline
\end{tabular}


Table 2. Properties of steel.

\begin{tabular}{ccccc}
\hline Steel & Yield stress $\sigma \mathrm{y}(\mathrm{MPa})$ & Tensile strength $\sigma \mathrm{t}(\mathrm{MPa})$ & Strain at failure & Young modulus ES (MPa) \\
\hline $6 \mathrm{~mm}$ bars & 518 & 544.28 & 0.0478 & 197,800 \\
$9 \mathrm{~mm}$ bars & 559 & 626.5 & 0.1934 & 203,680 \\
\hline
\end{tabular}

\subsection{Capping}

The model was in such a way that there was capping at both ends so that the applied load would be evenly distributed. Therefore, a $100 \mathrm{~mm}$ length normal concrete capping at both ends were added to the model so as to prevent it from premature cracking around the loading and supports areas. CDP was also used for modelling the normal concrete as proposed Tomasz [9].

\subsection{Polystyrene Core}

Polystyrene was used as an insulation material in the core layer. The polystyrene sheet was inserted in between the steel mesh. It had a mass density of $16 \mathrm{~kg} / \mathrm{m}^{3}$, a Young's Modulus of $0.896 \mathrm{MPa}$ and poison ratio of 0.4

\subsection{Boundary Condition and Loading}

The load, boundary condition, and field managers are used to view and manipulate the step wise history of prescribed conditions. The PLFP is simply supported along two lines parallel with the x-axis; the distance is 1800 mm for panel 1, 2 and 4 while it is $2300 \mathrm{~mm}$ for panel 3. The PLFP has been extended with a capping of 100 $\mathrm{mm}$ from the support in order to increase the area over which the reaction stresses can be distributed. There were two (2) concentrated loads exerted on two different points of the PLFP slab since this is a four points bending setup. The ultimate load is however computed by adding the two concentrated loads. Table 3 gives the dimensions and properties of all the PLFP while Figure 2 shows the setup of the panels and how they are modelled. The boundary conditions are applied in such a way that displacement will occur in the $\mathrm{z}$ direction which is in the direction of the applied load.

\section{Mesh Density Study}

For this study models with different mesh sizes were analysed to determine the best mesh density that would give a result which is closer to the experimental work and theoretical work. Figure 3 shows one of the panels after it has been meshed to an appropriate size. Table 4 shows the results of various mesh density for panel 2. The most suitable mesh density for this study was taking from the lowest percentage difference when compared to the sum of the theoretical and experimental ultimate strength value of the panel.

\section{Results and Verification}

\subsection{Ultimate Load}

The four panels are treated as separate models because they all have different dimensions. The ultimate strength achieved by the PLFP panels depended on various factors and not just the materials that are used for the analysis of various panels. The values for the ultimate strength of the panels were recorded by summing the values of P. $(\mathrm{p} / 2+\mathrm{p} / 2)$. Factors that had very significant effects on the ultimate strength include the panel's aspect ratio and the number of shear connectors used. Panel 4 had the highest ultimate load of $34.43 \mathrm{kN}$ while panel 3 had the lowest ultimate load of $16.21 \mathrm{kN}$ and this was as a result of their length to thickness ratio as Panel 4 had the highest and panel 3 the lowest. Table 5 shows the ultimate load and deflection of the four PLFP panels.

\subsection{Load Deflection Profile}

The maximum deflection of all four panels occurred at mid-span and from the load-deflection curves for Panel 1 to Panel 4, it was observed that Panel 3 had the highest deflection of $20.21 \mathrm{~mm}$ and Panel 4 achieved the lowest deflection of $8.51 \mathrm{~mm}$. This occurred due to the different length to thickness ratio which is a very important factor that helps in determining the value of the deflection. The length to thickness ratio of panel 1 was larger 


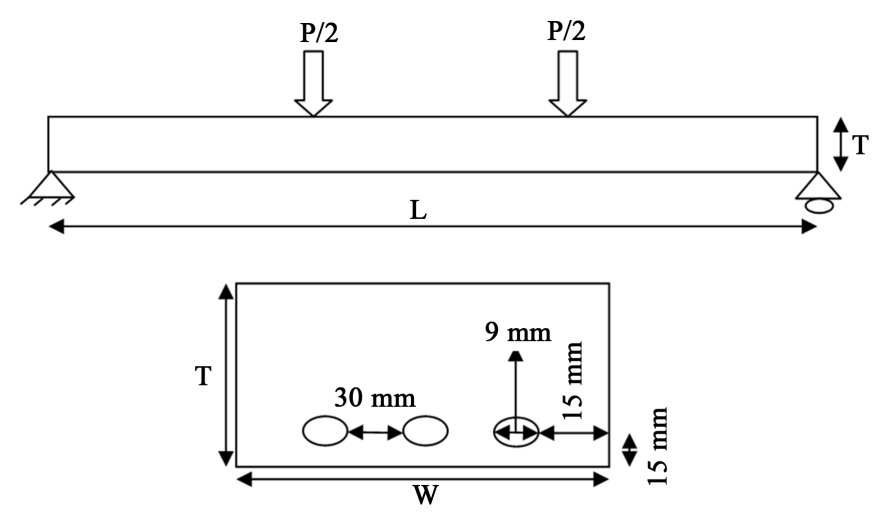

Figure 2. PLFP setup loading and boundary conditions.

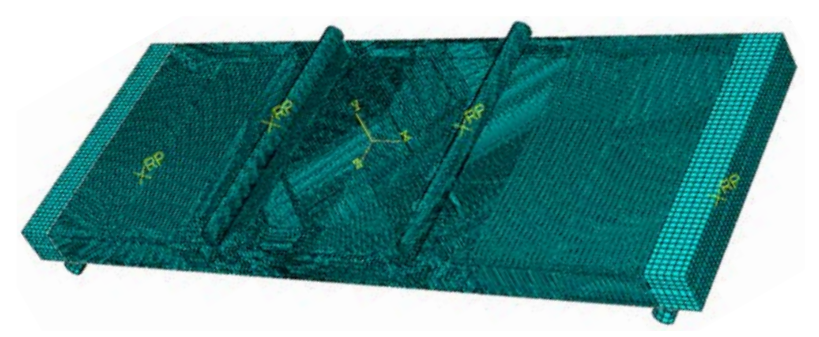

Figure 3. Mesh and boundary conditions.

Table 3. Dimension and properties of PLFP.

\begin{tabular}{cccccc}
\hline Panel & $\mathrm{L} \times \mathrm{W} \times \mathrm{T}(\mathrm{mm})$ & $\mathrm{L} / \mathrm{t}$ & Density $\left(\mathrm{Kg} / \mathrm{m}^{3}\right)$ & $\mathrm{F}_{\mathrm{cu}}(\mathrm{MPa})$ & Young modulus (Concrete) $(\mathrm{MPa})$ \\
\hline P1 & $2000 \times 750 \times 100$ & 20 & 1650 & 10.6 & 12,000 \\
P2 & $2000 \times 750 \times 110$ & 18.18 & 1900 & 20.1 & 16,700 \\
P3 & $2500 \times 750 \times 100$ & 25 & 1800 & 15.0 & 13,400 \\
P4 & $2000 \times 750 \times 150$ & 13.3 & 1800 & 15.0 & 13,400 \\
\hline
\end{tabular}

Table 4. Mesh density study.

\begin{tabular}{ccccccc}
\hline Model type & Total element & Total nodes & $\begin{array}{c}\text { Ultimate } \\
\text { load (KN) }\end{array}$ & $\begin{array}{c}\text { \% Difference } \\
\text { from experiment }\end{array}$ & $\begin{array}{c}\text { \% Difference } \\
\text { from Theory }\end{array}$ & Average difference \\
\hline Experiment & - & - & 25.63 & 0 & $2.3 \%$ & $2.3 \%$ \\
Theoretical data & - & - & 26.23 & $-2.2 \%$ & 0 & $-2.2 \%$ \\
C3D8R-1 & 2382 & 3361 & 29.35 & $-12.6 \%$ & $-10.6 \%$ & $-11.6 \%$ \\
C3D8R-2 & 12184 & 17816 & 29.12 & $-11.98 \%$ & $-9.9 \%$ & $-10.94 \%$ \\
C3D8R-3 & 18954 & 20472 & 28.96 & $-11.49 \%$ & $-9.4 \%$ & $-10.46 \%$ \\
C3D8R-4 & 33624 & 43615 & 23.44 & $9.3 \%$ & $11.90 \%$ & $10.6 \%$ \\
C3D8R-5 & 62307 & 83392 & 23.62 & $8.5 \%$ & $11.04 \%$ & $9.77 \%$ \\
C3D8R-6 & 153824 & 185995 & 23.3 & $9.8 \%$ & $12.5 \%$ & $11.15 \%$ \\
\hline
\end{tabular}

Table 5. Ultimate load and deflections at mid span.

\begin{tabular}{ccccc}
\hline Panel & Ultimate load, $(\mathrm{kN})$ & Deflection, $(\mathrm{mm})$ & Thickness (mm) & 100 \\
1 & 21.31 & 14.45 & 110 & 10.6 \\
2 & 23.62 & 15.08 & 100 & 15 \\
3 & 16.21 & 20.21 & 150 & 15 \\
\hline
\end{tabular}


than panel 2 but still achieved a lower deflection; this shows not only the length to thickness ratio of the PLFP affects the deflection but the value of their compressive strength. Figures 4-6 show the thickness, compressive strength and deflection of all panels.

\subsection{Validation of FEA}

The ultimate strength of the PLFP recorded from the finite element analysis is of an acceptable range except for Panel 1 which had a very high ultimate strength when compared to the experimental result. Table 6 shows the values of the ultimate strength and their maximum deflection values for experimental tests, FEA model and theoretical calculations. The maximum deflections of all four panels were observed at mid span of the slab as predicted by the experimental result. Figures 7(a)-(d) show the graphical representation to compare experimental test, FEA simulations and theoretical calculations.

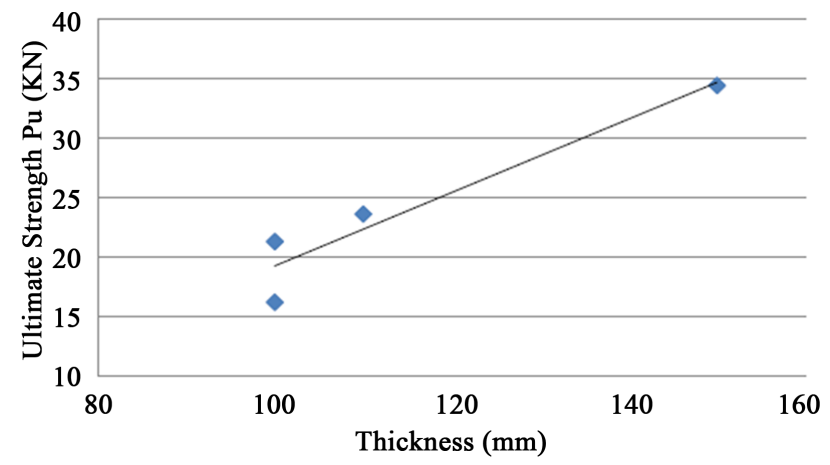

Figure 4. Ultimate load vs thickness.

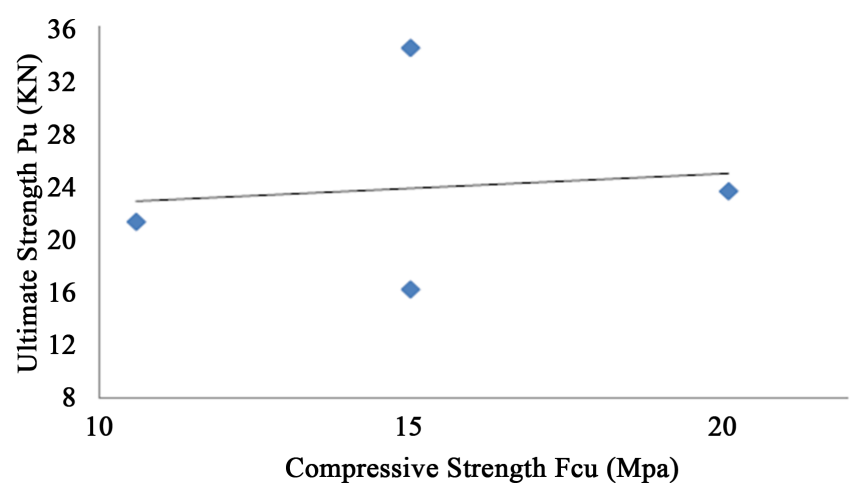

Figure 5. Ultimate strength vs compressive strength.

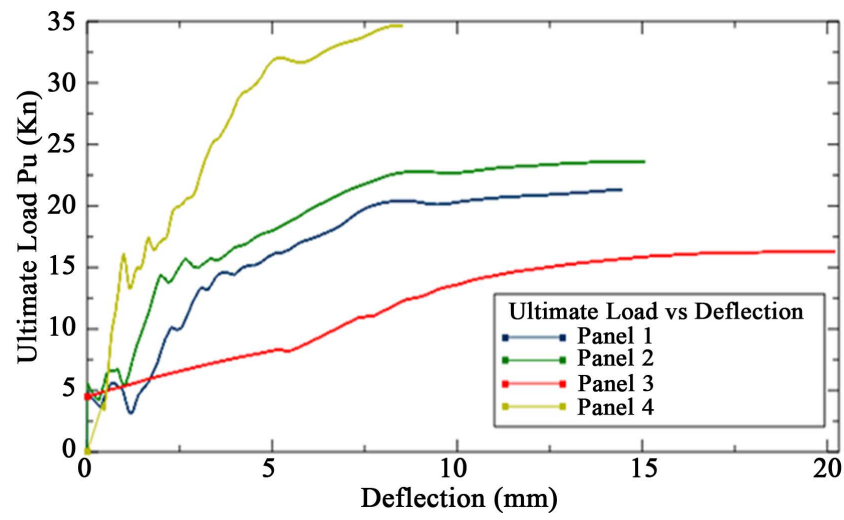

Figure 6. Load deflection curve. 


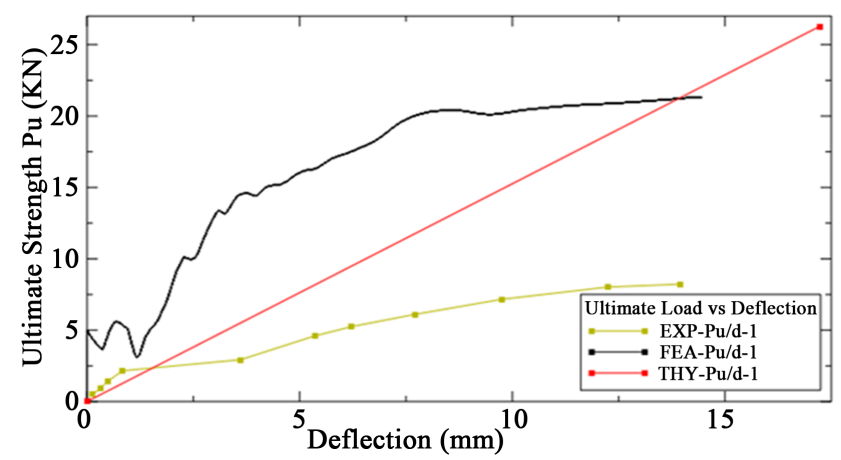

(a)

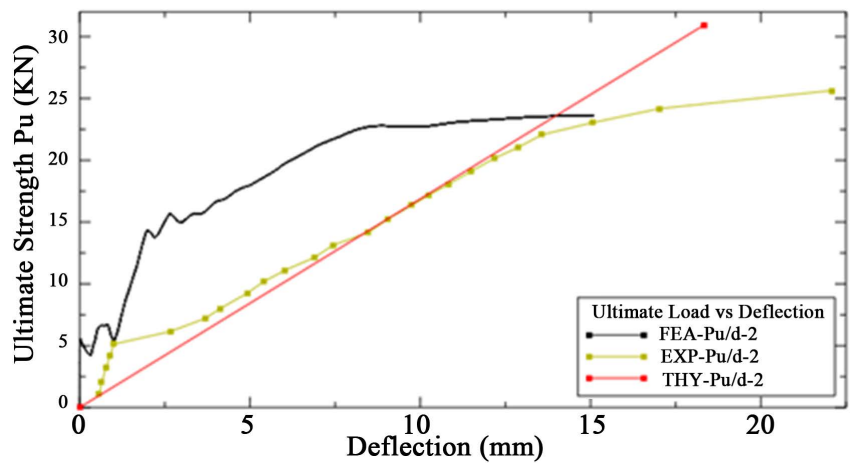

(b)

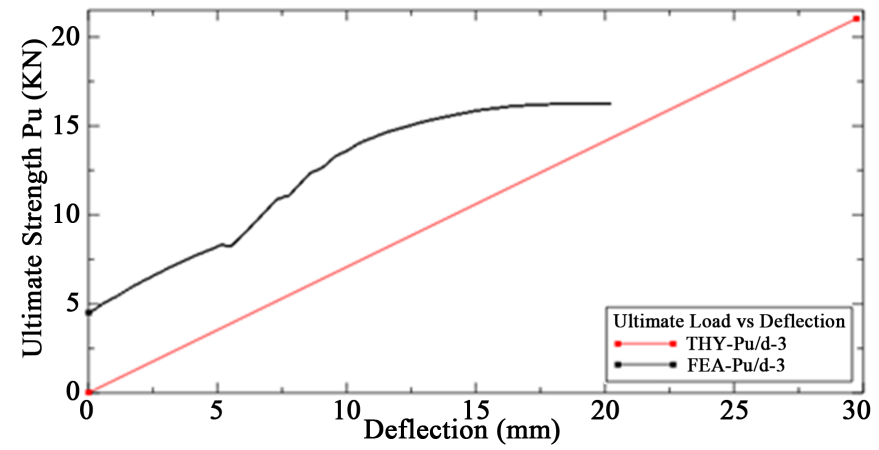

(c)

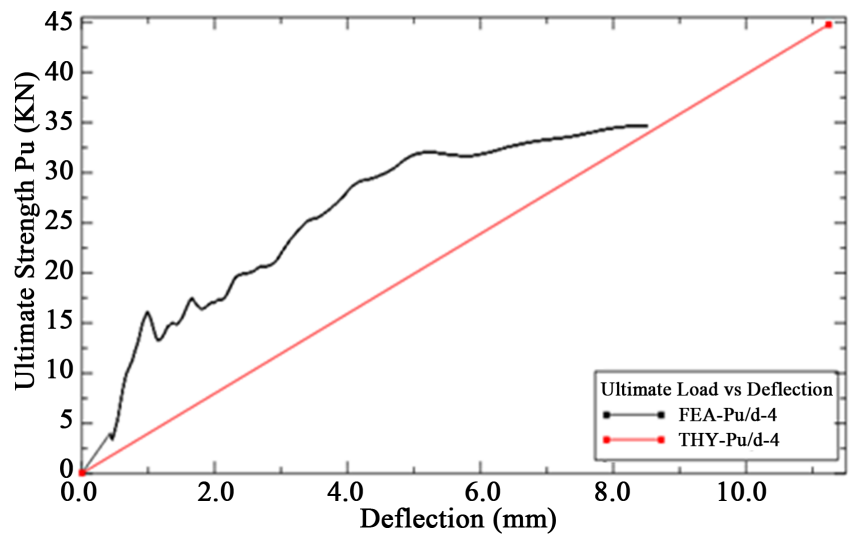

(d)

Figure 7. (a) Comparison of load deflection profile for Panel 1; (b) Comparison of load deflection profile for Panel 2; (c) Comparison of load deflection profile for Panel 3; (d) Comparison of load deflection profile for Panel 4. 
Table 6. Comparison of ultimate load and their maximum deflection.

\begin{tabular}{|c|c|c|c|c|c|c|}
\hline Panel & $\mathrm{P}_{\mathrm{u}} \mathrm{FEA}(\mathrm{kN})$ & $\begin{array}{l}\text { Deflection, } \\
(\delta) \text { FEA (mm) }\end{array}$ & $\mathrm{P}_{\mathrm{u}}$ experiment $(\mathrm{kN})$ & $\begin{array}{c}\text { Deflection, }(\delta) \\
\text { experiment }(\mathrm{mm})\end{array}$ & $\mathrm{P}_{\mathrm{u}}$ Theory $(\mathrm{mm})$ & $\begin{array}{l}\text { Deflection, }(\delta) \\
\text { theory }(\mathrm{mm})\end{array}$ \\
\hline Panel 1 & 21.31 & 14.45 & 8.23 & 13.94 & 26.27 & 17.22 \\
\hline Panel 2 & 23.62 & 15.08 & 25.63 & 22.07 & 30.93 & 18.33 \\
\hline Panel 3 & 16.21 & 20.21 & - & - & 21.03 & 29.74 \\
\hline Panel 4 & 34.43 & 8.51 & - & - & 44.77 & 11.24 \\
\hline
\end{tabular}

\section{Conclusions}

The purpose of this research was to study the numerical simulation for the structural behaviour of Precast Lightweight Foam Concrete Sandwich Panel slab under flexural loading. The four panels used for this study had different length to thickness ratio which was used to determine the effectiveness of the length and thickness of a slab when determining its ultimate flexural strength. The result obtained from this study was used to show the accuracy level of computer aided simulation software when compared with an experimental and theoretical study to determine the ultimate flexural load of PLFP. The following conclusions were made after the study.

1) The material properties for concrete damage plasticity were obtained from previous research work on concrete. They were carefully factorised to get the appropriate value for each of the panels.

2) The length to thickness ratio for each panel affected the value of the ultimate strength attained. Panel 3 and panel 4 had the highest and lowest length to thickness ratio respectively. Panel 3 had an ultimate strength of $16.21 \mathrm{kN}$ and a length to thickness ratio of $25 \mathrm{~mm}$ while panel 4 had an ultimate strength of $34.43 \mathrm{kN}$ and a length to thickness ratio of $13.33 \mathrm{~mm}$.

3) Although panel 1 and 3 had similar thickness but different comprehensive strength, it can be concluded that the compressive strength did not affect the value of the ultimate strength as much as its length to thickness ratio.

4) The ultimate strength increased as a result of an increase in thickness. Panel 3 had the least ultimate strength of $16.21 \mathrm{kN}$ while panel 4 had the highest recorded ultimate strength of $34.43 \mathrm{kN}$. Their thicknesses were $100 \mathrm{~mm}$ and $150 \mathrm{~mm}$ respectively.

5) The deflection of all 4 panels occurred at mid span.

6) The deflection value of all the panels was affected by their respective dimensions. Panel 3 with the highest length to thickness ratio had the highest value of deflection $20.21 \mathrm{~mm}$ while panel 4 had the lowest value of $8.51 \mathrm{~mm}$.

\section{References}

[1] Ries, J.P., Speck, J. and Harmon, K.S. (2010) Lightweight Aggregate Optimizes the Sustainability of Concrete, through Weight Reduction, Internal Curing, Extended Service Life, and Lower Carbon Footprint. Concrete Sustainability Conference, Arizona.

[2] Samidi, M.R. (1997) First Report Research Project on Lightweight Concrete. Research Work, Skudai.

[3] Mahfuz, H., Muhammad, S.I., Vijaya, K.R., Mrinal, C.S. and Shaik, J. (2004) Response of Sandwich Composites with Nanophased Cores under Flexural Loading. Composites: Part B Engineering, 55, 543-550. http://dx.doi.org/10.1016/j.compositesb.2003.11.004

[4] Flores-Johnson, E.A. and Li, Q.M. (2012) Structural Behaviour of Composite Sandwich Panels with Plain and Fibre Reinforced Foamed Concrete Cores and Corrugated Steel Faces. Composite Structures, 94, 1555-1563. http://dx.doi.org/10.1016/j.compstruct.2011.12.017

[5] Mohamad, N. (2010) The Structural Behaviour of Precast Lightweight Foamed Concrete Sandwich Panels as Load Bearing Wall. Doctoral Dissertation, Universiti Teknologi Malaysia, Johor, Malaysia

[6] Khalil, A.I. (2013) Structural Behaviour of Precast Foam Concrete Sandwich Panel (PLFP) with Double Shear Connector under Flexural Load. Master's Project, Batu Pahat.

[7] ABAQUS (2009) Standard User's Manual. Dassault Systèmes, Version 6.9.

[8] Mohamad, N., Goh, W.I. and Abdullah, R. (2013) Compression Test and Finite Element Analysis of Foamed Concrete Cube. Malaysian Technical Universities Conference on Engineering \& Technology, Kuantan.

[9] Tomasz, J. and Lodygowski, T. (2005) Quasi Static Failure Criteria for Concrete. Foundations of Civil and Environmental Engineering, 6, 1642-9303, 53-69. 